\title{
ÉTICA EMPRESARIAL, INTERACTIVIDAD Y CONEXIÓN EMOCIONAL: PARADIGMAS DE LA CULTURA CORPORATIVA DE LAS EMPRESAS EN LA WEB 2.0
}

Carlos Oliva-Marañón': Universidad Rey Juan Carlos. España. carlos.oliva.maranon@urjc.es

Alfonso De la Quintana-García-Pérez: Universidad Rey Juan Carlos. España. alfonso.delaquintana@urjc.es

\section{RESUMEN}

La Comunicación Corporativa 2.0 se ha consolidado como una nueva estrategia de las empresas para diferenciarse, ampliar sus mercados y llegar a más consumidores. El objetivo de esta investigación es evaluar, a través de sus Páginas Web corporativas, el posicionamiento en Internet de tres corporaciones presentes en el proceso emocionalvital de muchas personas. Se han seleccionado el Grupo Hospitalario Quirón, el Grupo Laureate International Universities y el Banco Santander. Se ha analizado la comunicación corporativa online de estas entidades a través de la imagen de marca, la visión de la misión, los valores promulgados, los eslóganes, los vídeos institucionales, el acceso a las redes sociales y las memorias corporativas. Por un lado, los resultados confirman la idoneidad de estas herramientas online como paradigmas de consolidación de la Comunicación 2.0; la visibilidad de estas entidades a través de las redes sociales; así como la promulgación del compromiso, el dinamismo, la innovación, el liderazgo, la fortaleza, el espíritu de grupo, la internacionalidad, la orientación profesional y el enfoque de resultados como rasgos diferenciadores de estos grupos corporativos. Por otro lado, se constata la ocupación y preocupación de las empresas por el acercamiento a los usuarios de la Web 2.0; el reforzamiento de la cultura y la identidad de una compañía concretada en sus valores y en su misión para lograr su vinculación con las personas y la consolidación de su actividad emocional.

PALABRAS CLAVE: Empresas Web 2.0 - Cultura corporativa - Ética empresarial Conexión emocional.

\footnotetext{
${ }^{1}$ Autor correspondiente:

Carlos Oliva Marañón: Profesor de Comunicación de la Universidad Rey Juan Carlos. España.

Correo: carlos.oliva.maranon@urjc.es
} 


\title{
BUSINESS ETHICS, INTERACTIVITY AND EMOTIONAL CONNECTION: PARADIGMS OF CORPORATE CULTURE OF COMPANIES IN THE WEB 2.0
}

\begin{abstract}
Corporate Communication 2.0 has established itself as a new strategy for companies to differentiate themselves, expand their markets and reach more consumers. The objective of this research is to evaluate, through their corporate websites, online positioning of three corporations are present in the vital-emotional process for many people. It has selected Quiron Hospital Group, Laureate International Universities Group, and Santander Bank. It has analyzed the online corporate communication of these companies through brand image, the vision of the mission, the values promulgated, slogans, institutional videos, access to social networks and corporate memory. Similarly, It has compared the duration of institutional campaigns, matching soundtracks, the presence of speakers, the appearance of images of the facilities, the statements of businessmen, professionals, teachers and students and the inclusion of corporate reports Web pages. On one hand, the results confirm the suitability of such online tools as paradigms consolidation Communication 2.0, the visibility of these institutions through social networks like Facebook and Twitter, as well as the enactment of the commitment, dynamism, innovation, leadership, strength, team spirit, internationality, career guidance and focus results as distinguishing features of these corporate groups. Furthermore, they are found to occupation and concern for companies reaching out to users of the Web 2.0, the strengthening of the culture and identity of a company materialized in its values and in its mission to achieve its link with people and consolidation of emotional activity.
\end{abstract}

KEYWORDS: Companies Web 2.0 - Corporate culture - Business Ethics - Emotional connection.

\section{INTRODUCCIÓN}

Uno de los factores que se establece como fundamental para definir la actividad empresarial es el hecho de que, en muchas ocasiones, se emplee a través de los medios de comunicación masiva. De este modo, llega a un número importante de personas, por lo cual, el desarrollo de las empresas está muy relacionado con el de los medios. El origen de la difusión de las empresas suele fijarse con el nacimiento de la imprenta, impulsada por Johannes Gutenberg en el siglo XV. Este instrumento de difusión del saber hace posible que un considerable contenido de información pueda llegar al gran público. Principalmente, son tres los factores precursores del nacimiento y el desarrollo de las empresas de comunicación: la supresión de la censura previa y del privilegio de imprimir libros y publicaciones; los avances en los medios de transporte; y la liberalización del comercio. Los primeros periódicos literarios y científicos como Le Journal des Savants (1665) surgieron en París y, en 1702, se fundó el Daily Courant, el primer diario del Reino Unido. De esta forma, el sistema de publicaciones periódicas 
se estableció por tres motivos: a) por su inmediatez; b) por su amplitud de impacto; y c) por su precio.

En lo relativo a las compañías, sobresalen las dedicadas a la difusión de la información. Así, el término "Empresa Informativa" se compone de dos vocablos que marcarán los estudios científicos y prácticos de esta disciplina. Por una parte, el término "Empresa" lleva a los investigadores a interesarse por todos aquellos conocimientos derivados de la Teoría de la Economía de la Empresa. Por otra parte, el vocablo "Informativa", que conduce a los conocimientos emanados de la Teoría de la Información. Tallón (1992) define la disciplina "Empresa Informativa" como "el conjunto de conocimientos sistemáticos que tienen por objeto el estudio de unidades económicas de producción y difusión de mensajes de información con ánimo de lucro".

En relación con la actividad empresarial y su difusión mediante técnicas de promoción, Carlos Sotelo Enríquez, Profesor de Comunicación Institucional en la Universidad de Navarra, afirma: "La Publicidad Institucional de cualquier empresa reúne tres elementos" (Sotelo, 2007, p. 160):

a) Como procedimiento informativo, aprovecha las ventajas del anuncio publicitario: seguridad en la difusión, fuerza retórica y visual y control del contenido.

b) Transmite hechos, ideas o juicios relacionados con el conjunto de la Institución, lo que facilita al público poseer un concepto integral de la entidad. Sus promotores comenzaban a ser conscientes de que, además de información sobre asuntos particulares, los ciudadanos necesitan albergar percepciones generales sobre las Instituciones, a fin de guiar su comportamiento con respecto a ellas.

c) En su planteamiento subyace un modelo de comunicación unilateral, que encomienda a los destinatarios el papel de receptores. Éstos no participan en la formación de las ideas mediante las que se quiere dar cuenta de la Institución, sino que solo aceptan o rechazan su contenido. De ese modo, se erige una barrera entre los dos sujetos de la relación informativa, que más tarde se explicó con la dicotomía identidad/imagen.

En la actualidad, en un entorno empresarial cada vez más competitivo, la evolución de la tecnología, unida a la crisis económica, está provocando que las compañías se vean en la necesidad de diferenciarse y ampliar sus mercados para llegar a más consumidores. Dado este escenario, las empresas han visto en Internet un instrumento importante para ampliar las oportunidades de negocio. Por ello, han incorporado nuevos avances en sus gestiones. Entre ellos, la Comunicación Corporativa 2.0 (Stein, 2010), que aborda las nuevas estrategias de comunicación de las empresas, como por ejemplo, entre otras muchas, el posicionamiento Web en Google, el desarrollo de blogs corporativos o la irrupción en las redes sociales como Facebook o Tuenti.

Con la entrada en escena del concepto 2.0, Cabrera (2010, p. 168) señala: "Las audiencias son ahora activas participando de diversas formas en el proceso comunicativo: aportando opiniones (foros, encuestas, chats) y produciendo contenidos 
(textos, fotos, vídeos)". Barroso (2008, p. 120) comenta que el concepto 2.0, acuñado por O'Reilly (2005), "no representa solo un modelo tecnológico, sino también social y empresarial. Un nuevo modelo de Internet basado en una arquitectura de participación e interacción entre redes sociales". El usuario es un sujeto individual, libre y tecnológicamente capaz de emitir un juicio sobre todo lo que le rodea, lo que ve, lo que consume (Aced, et al., 2009).

La Web 2.0 ha generado toda una revolución en el ámbito de la publicidad, en particular, y la comunicación empresarial, en general. La comunicación integral, hoy más que nunca, pasa por integrar precisamente en el centro del proceso al consumidor, actual y potencial, según la filosofía 2.0. Los nuevos entornos digitales (redes sociales, blogs, plataformas de videos digitales, microblogging, la geolocalización al servicio del mobile marketing, etc.) favorecen la orientación empresarial basada en las relaciones (la filosofía del client first); la generación de branding social; la segmentación y personalización de mensajes; la evangelización de la marca a través de la prescripción y la viralidad; y la puesta en marcha de un experiential marketing que genere customer engagement (Castelló, 2010, pp. 79-98).

Según Celaya (2008, pp. 146-147), "el principal retorno que buscan las empresas a la hora de invertir en tecnologías Web 2.0 es la mejora de la interacción con sus clientes e incrementar sus ventas". En este sentido, la gestión del conocimiento en estos entornos participativos ayuda a generar valor para los públicos de la organización (Ros, 2008, p. 24). Compartir, comunicar, conversar y cooperar son los cuatro pilares de los nuevos entornos digitales. En los Social Media, como canales no solo de información y comercialización, sino también de conversación, el consumidor se coloca en el centro de la relación con las marcas y, ahora más que nunca, de él depende el éxito empresarial. La capacidad de generar conversaciones, pasando del monólogo al diálogo, convierte al consumidor en el centro de todo el sistema (Madinabeitia, 2010, p. 49).

Existen cuatro elementos fundamentales que configuran a todas las empresas y que las dotan de una determinada personalidad que las diferencian de las demás:

La misión. Se entiende como lo que la propia empresa es y se configura como la razón de su existencia. Este elemento es el principal constituyente de una compañía, ya que dependiendo de cómo se defina va a influir en los demás: los fines, los objetivos y las estrategias. Además, la misión de las empresas puede dividirse en dos tipologías:

- General. Aquella misión que, por consenso social, se atribuye a compañías semejantes. Por ejemplo, la sociedad comprende que las empresas informativas están, principalmente, para informar de una manera veraz e independiente de otros intereses. Así, toda entidad que quiera incluirse tiene que asumir lo que socialmente se le asigne.

- Específica. Es la misión que cada empresa se otorga a sí misma y que la hace ser diferente de las demás. Estas misiones específicas suelen 
explicitarse en las publicaciones oficiales de las corporaciones y en las respectivas páginas Web en el apartado "Quiénes somos". También, en las memorias anuales o en una carta de su presidente en la que se hace referencia a esta misión, poniéndola en consonancia con los objetivos alcanzados el año en curso.

> Los fines. Son aquellos logros que quiere conseguir la empresa para hacer realidad su misión. Los fines pueden y deben ser de todo tipo: tanto de logros comerciales, como de organización y gestión de recursos humanos. Por ejemplo, si se trata de una agrupación empresarial que quiere informar verazmente a la sociedad, habrá que lograr que todas las informaciones sean veraces. Por tanto, se dotará de todos los medios para lograrlo. En consecuencia, un fin adecuado a la misión de la empresa es dotarse de los medios para lograr que sus informaciones sean verdaderas.

$>$ Los objetivos. Son aquellos logros particulares de una empresa por los que consigue sus fines. Los objetivos deben deducirse de los fines y formar partes complementarias con ellos. Además, deben estar en consonancia con la misión de la entidad.

$>$ Las estrategias. Son aquellas gestiones que se han de realizar para alcanzar los objetivos y los fines. Por tanto, están al servicio de ellos, por lo que no pueden contradecir a ninguno de ellos.

En definitiva, en opinión del profesor José Luis Piñuel (1997, p. 92):

La comunicación social, aplicada en organizaciones, denota un sistema peculiar de comunicación en el que el intercambio de expresiones entre actores colectivos (como emisores, las organizaciones; y como receptores, sus públicos o audiencias) se somete a los procesos de producción y consumo de un servicio convertido en mercancía profesional.

\section{METODOLOGÍA}

Para la realización de esta investigación, se han seleccionado tres entidades corporativas que, en mayor o menor medida, se encuentran presentes a lo largo del ciclo vital de una persona:

> Una firma hospitalaria, el Grupo Hospitalario Quirón, baluarte de la sanidad privada en España, con 11 centros hospitalarios.

> Un consorcio de Universidades, el Grupo Laureate International Universities, paradigma de la Educación Superior mundial con tres Universidades en el territorio nacional (Universidad Europea de Madrid, Universidad Europea de Valencia y Universidad Europea de Canarias). 
> Una entidad financiera, el Banco Santander, principal Grupo de Finanzas en España y América Latina con más de 15.000 oficinas.

Igualmente, se ha analizado la comunicación corporativa online de estas empresas a través de los siguientes elementos:

$>$ La imagen de marca.

$>$ La visión de la misión.

$>$ Los valores promulgados.

$>$ Los eslóganes.

$>$ Los vídeos institucionales.

$>$ El acceso a las redes sociales.

$>$ Las memorias corporativas.

Por tanto, los objetivos han sido:

> Evaluar, a través de las Páginas Web corporativas, el posicionamiento en Internet de tres empresas con muy diferentes: una Entidad Bancaria, un Grupo Hospitalario y una Red Internacional de Universidades.

$>$ Verificar la ocupación y la preocupación de las empresas por el acercamiento a los usuarios de la Web 2.0, así como el reforzamiento de la cultura y la identidad de una compañía concretada en sus valores y en su misión para lograr su vinculación con las personas y la consolidación de su actividad emocional.

\section{ANÁLISIS Y DISCUSIÓN 3.1 Grupo Hospitalario Quirón.}

El Grupo Hospitalario Quirón toma el nombre de un centauro mitológico, hijo de Cronos y Fílira. En la Grecia Clásica, la figura de Quirón ilustraba la bondad de un descendiente directo de Zeus, un centauro que, a diferencia de sus semejantes, no participaba en las guerras, sino que ejercía labores de médico y cirujano. Quirón fue el educador de hijos de reyes y un consejero sabio, amigo de los hombres, que cedió su inmortalidad a Prometeo, el protector de la civilización por ser el creador del ser humano en la mitología griega. Quirón fue el nombre que el Dr. D. Publio Cordón escogió al fundar la primera clínica en Zaragoza, a finales de los años cincuenta. Un proyecto que nacía con la misma devoción por la entrega que el Centauro, una figura mitológica que simbolizaba la ayuda al prójimo.

Quirón inauguró un centro en Valencia en 1989 y, posteriormente, en San Sebastián y Barcelona. Su actividad se basa en tres pilares fundamentales: alta tecnología, cuadro médico experimentado y concentrar todo el esfuerzo para satisfacer al paciente. Gracias a la coordinación de esfuerzos entre especialistas y a la constante implantación de criterios de mejora, los centros se sitúan a la vanguardia en los diferentes campos de la medicina y están preparados para la aplicación de tratamientos médicos de alta complejidad. Tras la apertura de los dos nuevos hospitales Quirón en Málaga y 
Vizcaya a finales de 2009, se amplían sus prestaciones en Valencia. Además, en julio de 2012, se aprobó la fusión entre Quirón y USP Hospitales, lo que ha permitido a ambos grupos compartir conocimiento, optimizar recursos y procesos y reforzar la calidad asistencial. Igualmente, se posiciona como el primer grupo sanitario español en número de pacientes atendidos en superficie asistencial, con más de 2.250 camas hospitalarias, 6.500 médicos vinculados y 600.000 estancias hospitalarias al año.

\subsubsection{Misión, visión y valores}

La misión de Quirón es cuidar la salud y ofrecer un servicio a la sociedad de máxima calidad, gestionando una moderna estructura hospitalaria de vanguardia formada por equipos competitivos, vocacionales y fuertemente comprometidos. En cuanto a la visión, Quirón es un grupo hospitalario privado reconocido por: superar las expectativas de pacientes, médicos e instituciones a través de la mejora constante de la calidad en el capital humano y tecnológico; promover la innovación y la investigación; y tener una red eficiente de hospitales que ofrezcan una excelencia asistencial a través de la atención integral al paciente.

Por lo que respecta a los valores, el Grupo Hospitalario Quirón promueve los siguientes:

> Compromiso. Todos los esfuerzos se dirigen de manera que la relación empresa-trabajadores tenga metas y objetivos comunes para cumplir con la visión y misión teniendo como base una responsabilidad compartida.

> Innovación. Se aplican los procedimientos de atención universalmente aceptados en la comunidad académica y científica, basados en un programa coste-efectividad, empleando una tecnología punta que promueva una pronta recuperación integral del paciente de acuerdo con las normas de calidad documentadas.

- Espíritu de Grupo. Se promueve la integración de hospitales y profesionales con diferentes culturas, hábitos y procedencias.

\subsubsection{Eslogan}

El eslogan del Grupo Quirón, Manos expertas, promulga, con solamente dos vocablos, la calidad de sus servicios avalada por la experiencia y cualificación de su equipo médico y la alta tecnología empleada en sus equipamientos.

\subsubsection{Imagen de marca}

La marca Quirón se posiciona como un referente en lo relativo a fuente de información para la prensa especializada en información sanitaria. Esto se debe a su disposición a la hora de compartir su conocimiento con la sociedad. Como punto de encuentro entre sociedad y equipos médicos, se encuentran los Departamentos de Comunicación de los Hospitales Quirón, desde donde se gestiona la divulgación de toda esta 
información. En 2011, fruto de esta estrategia, se enviaron 71 notas de prensa a medios de comunicación con informaciones siempre relativas a hitos de carácter médico o a la creación de nuevos servicios. Estas acciones, junto con las ruedas de prensa (8) y encuentros directos con periodistas, entre otros, permitieron a los distintos hospitales del Grupo Hospitalario Quirón superar las 1.600 apariciones en medios de comunicación.

En el ámbito de la publicidad, el Grupo Hospitalario también dio continuidad a distintas campañas, tanto en medios escritos (generales, regionales, locales), como radiofónicos o digitales. A su vez, 2011 fue un año en el que Quirón desarrolló diversos proyectos digitales, como la nueva Web Quirón de Oftalmología, presentada en febrero, y que, en 2011, recibió 60.133 visitas. Además, se puso en marcha un sitio Web especializado en Reproducción Asistida en el mes de septiembre (como el anterior, también traducido al inglés y francés) que, al cerrar el año, ya había recibido 25.871 visitas. Por otra parte, en la estrategia 2.0. de Quirón, el canal YouTube reprodujo sus vídeos en 397.330 ocasiones. Igualmente, en 2011, se inauguró la página oficial en la Red Social Facebook.

En cuanto a la industria editorial, se editaron tres nuevos libros: 14 historias de superación narradas en primera persona, una Guía práctica de medicina reproductiva y Edificios que sanan. Además, en 2011 se publicaron tres nuevos números (11, 12 y 13) de la revista GHQ, que ofrece contenidos de distintos ámbitos relacionados con la medicina y los hábitos de vida saludables. Con una tirada de 40.000 ejemplares y un aumento del número de páginas, GHQ es una revista plenamente consolidada entre los lectores. Igualmente, se publicaron guías dirigidas al paciente (como las realizadas por Quirón Madrid y San Sebastián para el tratamiento de lesiones, y que se repartieron gratuitamente en actos deportivos patrocinados), así como folletos con información de especialidades médicas y productos, y los correspondientes boletines internos dirigidos al personal.

Por lo que respecta a las redes sociales y los canales audiovisuales, el Grupo Quirón está presente en Facebook, Twitter y YouTube.

$>$ En Facebook, se presenta un sumario con celebraciones destacadas como el Día Internacional de la lucha contra el Cáncer, el Día Internacional de la Mujer o el Día Europeo de Prevención Cardiovascular siempre relacionándolos con consejos y recomendaciones acerca de cómo mejorar la salud. Igualmente, se abordan cuestiones de salud que afectan a una parte importante de la población como el trastorno del sueño y el cuidado de los pies. Su eslogan, Siempre contigo, refuerza y afianza la confianza del paciente en el equipo médico y la atención recibida. También se muestra un boletín de noticias (conferencias, seminarios, talleres y exposiciones) relacionadas con la salud, lo que refuerza el alto grado de implicación del grupo hospitalario con sus pacientes, informándoles de todo lo relacionado con la salud que les pueda interesar. 
$>$ En Twitter, los enfermos expresan al equipo médico sus dudas y preocupaciones acerca de su salud. De esta forma, se establece un "feedback" entre paciente y médico a través de las redes sociales.

> En YouTube, se muestra un vídeo corporativo de 3 minutos de duración, en el que se explican sus principales características (tecnología y equipo médico), refrendadas con diferentes fotografías tanto de los edificios principales de cada centro hospitalario como de su interior (quirófanos, salas de espera, etc.). Igualmente, existen vídeos corporativos clasificados por Especialidades y Servicios (Oftalmología, Reproducción Asistida, Obstetricia y Ginecología, Técnicas Médicas, Oncología, Dermatología, Traumatología, Fisioterapia, Neurología, Diagnóstico por Imagen, Psiquiatría, Unidad del Sueño, Alergología, etc.).

\subsection{Laureate International Universities.}

Laureate International Universities es una Red internacional de Instituciones de Educación Superior fundada en Estados Unidos en 1998. Actualmente, cuenta con más de 65 Universidades en 29 países de los cinco continentes, más de 100 Campus y alrededor de 750.000 alumnos. La Red Laureate nació con el propósito de conseguir que la Educación Superior fuera más accesible para un mayor número de estudiantes, independientemente del país de procedencia, formando individuos que aporten sus conocimientos para el desarrollo y crecimiento de las comunidades. Los países en los que Laureate se encuentra representada son: Alemania, Chipre, España, Francia, Italia, Países Bajos, Reino Unido, Suiza, Turquía, Portugal, Brasil, Chile, Costa Rica, Ecuador, Estados Unidos, Honduras, México, Panamá, Perú, Australia, China, Malasia, Indonesia, Arabia Saudí, India, Japón, Nueva Zelanda y Marruecos.

\subsubsection{Misión, visión y valores}

Su misión principal es la de satisfacer la creciente demanda de Educación Superior en todos los países, proporcionando a sus estudiantes las herramientas necesarias para alcanzar sus metas profesionales y personales. Para ello, cuenta con una amplia oferta de programas de Educación Superior orientados al mundo laboral y sus necesidades. $\mathrm{Su}$ visión como red internacional es facilitar el acceso a la Educación Superior a todos los niveles a través de un mismo denominador común: el desarrollo de las personas mediante el aprendizaje teórico-práctico adecuado a las necesidades del actual mercado global altamente competitivo.

Los alumnos siguen la filosofía Laureate, guiada por el compromiso de crear programas académicos que aporten:

Internacionalidad, ofreciendo programas bilingües, de intercambio y doble titulación entre las Universidades de la Red, compartiendo currículos y dando así acceso a profesorado de otros países. 
> Innovación tecnológica como materia y como medio de aprendizaje e investigación.

> Orientación profesional, proporcionando a los estudiantes las habilidades profesionales adecuadas para su aplicación en el mercado laboral.

$>$ Enfoque en resultados, reflejado en el éxito profesional logrado por los alumnos de Laureate. En total, se ofrecen más de 130 programas de Educación Superior en las áreas de Salud, Hostelería, Business, Derecho, Educación, Arquitectura, Ingeniería, y Tecnología de la Información. En conjunto, todas las áreas necesarias para triunfar en una sociedad global como la actual.

La multiculturalidad, el respeto a las creencias y modos de vida y las conexiones globales son claves para su desarrollo. Una parte esencial de su filosofía es respetar la historia, cultura y formas de vivir de las comunidades donde se encuentra. Por lo que respecta a los profesores, se les ofrecen las Becas Richard W. Riley para facilitar su movilidad entre las Universidades de la Red. El éxito de los alumnos no depende solamente de ellos mismos, sino también del impacto que tienen sus docentes en el desarrollo de la sociedad. Un profesorado altamente cualificado permite ser agentes de cambios positivos y así fortalecer a sus comunidades. En este sentido, cada Institución Laureate cuenta con su propio comité de asesoría académica avalado por la experiencia de sus miembros con el fin de garantizar una elevada calidad. En consecuencia, la Red Laureate se define en tres paradigmas: internacionalidad, calidad académica y garantía de éxito profesional.

\subsubsection{Eslogan}

El eslogan del Grupo Laureate International Universities, The most trusted name in Global Higher Education, la Red de mayor confianza en la Educación Superior Global, hace referencia a su reforzamiento como marca y posicionamiento mundial en el marco de la Educación Superior.

\subsubsection{Imagen de marca}

Laureate International Universities está presente en las principales redes sociales como Facebook o Twitter y otros sitios Web como Google+, Vimeo, Flickr, Pinterest y Tumblr. Además, la Red se ha consolidado como líder mundial en la educación online, adaptando sus programas académicos a cualquier perfil de estudiante, ya sea procedente del Bachillerato o un profesional que necesite ampliar su formación para mejorar sus expectativas profesionales. En muchos países, la mejora de la prosperidad requiere la creación de programas que aborden las necesidades de estudiantes adultos. Estos alumnos, muchos de los cuales no tuvieron la oportunidad de completar o incluso comenzar una titulación universitaria, a menudo, deben equilibrar el trabajo y la Universidad con la consecución de sus objetivos. 
La Universidad Europea de Madrid, con sede en Villaviciosa de Odón y La Moraleja (Madrid), ha diseñado la Universidad Personal con programas específicos para profesionales. La metodología está enfocada a la flexibilidad y la facilidad para compaginar los estudios online con los presenciales. Igualmente, cada estudiante cuenta siempre con un tutor personal encargado de asesorarle y resolver las dudas que le puedan surgir, tanto a nivel académico como personal o profesional. De esta forma, la Universidad Personal se fundamenta en tres características: flexible (el alumno decide cuándo empezar y a qué ritmo estudiar); personalizada (se adapta a las circunstancias personales y le permite elegir asignaturas online o presenciales); interactiva (con herramientas de contacto directo con profesores, compañeros y empresas).

Por lo que respecta a las redes sociales y canales audiovisuales, Laureate International Universities está presente en Facebook, Twitter y YouTube.

$>$ En YouTube, se presenta un vídeo corporativo, de 4 minutos de duración, en el que se explican sus principales características y filosofía educativa, acompañadas de fotografías alusivas a las principales Universidades. Igualmente, se ofrecen declaraciones de profesores y alumnos.

> En Facebook, se muestran imágenes de los diferentes Campus y se describen las características diferenciadoras de las principales Universidades asociadas a este consorcio de Educación Superior. Además, contiene un foro en el que los usuarios expresan sus opiniones acerca de las diferentes Universidades, así como de las conferencias, seminarios y celebraciones.

> En Twitter, se aprecian diversos Tweets en los que se ofrece información y comentarios acerca de las distintos Centros de Educación Superior.

En Vimeo, se exhibe un vídeo corporativo, de 4 minutos de duración, en el que se describen sus principales instalaciones, así como declaraciones de profesores y alumnos.

Igualmente, para reforzar su imagen de marca, el Grupo Laureate Internacional Universities elabora un dossier de prensa mensual con las noticias más relevantes.

\subsection{Banco Santander.}

El Banco Santander es una de las entidades que, por su fortaleza, ejerce una mayor influencia ante la opinión pública. Sin duda, es una tarea de años y de buena comunicación. Otro aspecto importante ha sido su fusión con Banesto. La Web del Santander cumple los requisitos de la Responsabilidad Social Corporativa: "implica que, además del cumplimiento estricto de las obligaciones legales, técnicas y económicas, la empresa integra las preocupaciones sociales, laborales, 
medioambientales y humanas en sus procedimientos y políticas mediante un compromiso voluntario". La empresa incluye "la dimensión moral en la toma de decisiones, en la planificación estratégica y en el diseño de las políticas, de tal manera que se involucren todas sus áreas de negocio" (Castelló, 2010, p. 41).

Los problemas sociales se reflejan a primera vista en su relación con la Universidad: desde las becas hasta los premios. Es una manera de llegar a los jóvenes, clientes potenciales, con hechos y no con palabras. El mensaje está muy diseñado, ya que, en la actualidad, los jóvenes desean realidades y compromisos.

Del mismo modo, hay que destacar otros paradigmas del Grupo Santander presentes en su Web:

La abundancia de información.

> Los aspectos sociales no se centran solo en la Universidad, sino también en la cooperación, el voluntariado y los microcréditos.

> El Grupo Santander concede gran importancia a la sostenibilidad, aspecto que se ve reflejado en su Web mediante su interacción con los jóvenes, invitándoles a insertar su Currículum Vítae para ofrecerles la posibilidad de integrarse en su plantilla.

Se puede encontrar rápidamente cualquier memoria o documento de la entidad en la Web.

\subsubsection{Visión y valores}

Desde su Página Web se transmiten los cuatro ejes de visión estratégica:

> Gran Grupo Financiero Internacional. Se ha consolidado como el mayor Banco de la Zona Euro y permanece entre los primeros del mundo, tanto por capitalización como por beneficios.

$>$ Satisfacción integral de las necesidades financieras de los clientes. Desarrolla todas las soluciones de servicios y productos bancarios posibles destinados a particulares de todos los niveles de renta, empresas de cualquier tamaño, grandes corporaciones privadas, instituciones públicas y comunidades universitarias.

$>$ Valor creciente para los accionistas. Desde 2007, año tras año, ha cumplido su objetivo de retribuir al accionista con un mínimo de 0,60 euros por acción, a pesar de la crisis económica mundial global.

$>$ Presencia relevante en mercados locales diversificados. Es el Banco líder del sector con una presencia muy relevante en diez mercados muy importantes y una adecuada combinación entre economías maduras y emergentes. Todas las filiales están respaldadas por sus políticas corporativas y sus capacidades globales de organización y tecnología. 
La organización refleja sus valores corporativos en todos los mercados donde opera:

Dinamismo. Lleva la iniciativa, tiene agilidad para descubrir y explotar las oportunidades de negocio antes que sus competidores y son flexibles para adaptarse a los cambios del mercado.

> Fortaleza. La solidez del balance y la prudencia en la gestión del riesgo son las mejores garantías para la capacidad de crecimiento y de generación de valor a largo plazo para los accionistas.

$>$ Liderazgo. Su vocación es el liderazgo en todos los mercados donde están presentes, contando con los mejores equipos humanos y estando orientados al cliente y a resultados.

> Innovación. Buscan permanentemente productos y servicios que cubran las nuevas necesidades de los clientes y les permitan obtener incrementos de rentabilidad superiores a los de la competencia.

$>$ Calidad de servicio y satisfacción de clientes. El cliente está en el centro del modelo de negocio de Banco Santander, es un banco para sus ideas. Quieren entender sus necesidades, responder con soluciones innovadoras y construir relaciones de confianza a largo plazo.

> Ética profesional y Sostenibilidad. Más allá del estricto cumplimiento de Leyes, códigos de conducta y normas internas, los profesionales del Santander integran en el desempeño de su actividad el compromiso del Banco con el progreso económico, social y medioambiental de las comunidades donde está presente.

\subsubsection{Eslogan}

El valor de las ideas es el lema que expresa a los clientes, a los accionistas y a la sociedad en general, por lo que se deduce que toda su fortaleza, liderazgo y capacidad están a su servicio para ayudarles a hacer realidad sus proyectos.

\subsubsection{Imagen de marca}

En YouTube, se muestra un vídeo, de 5,47 minutos de duración, en el que se realiza una analogía de una carrera de Fórmula 1 para explicar las principales dificultades que ha tenido la entidad en los últimos meses y cómo ha logrado superar la crisis económica. En Facebook, se encuentran noticias relacionadas con el Banco Santander y se ofrecen descuentos en la adquisición de entradas de cine, viajes, estancias y otras ofertas de ocio para clientes de la entidad financiera. Además, se obtiene información acerca del equipo de Fórmula 1 de Fernando Alonso, del que la Corporación Santander es patrocinadora. En Twitter, existen diversos Tweets en los que se informa acerca de las últimas novedades del Grupo Santander. 
Empresas Web 2.0 - Cultura corporativa - Ética empresarial - Conexión emocional

Tabla 1. Vídeos corporativos y presencia en las Redes Sociales

\begin{tabular}{|c|c|c|c|}
\hline Elemento & $\begin{array}{c}\text { Grupo } \\
\text { Hospitalario } \\
\text { Quirón } \\
\end{array}$ & $\begin{array}{c}\text { Laureate } \\
\text { International } \\
\text { Universities }\end{array}$ & Banco Santander \\
\hline Duración & 3,00 min. & 5,33 min. & 5,47 min. \\
\hline Banda sonora & SÍ & SÍ & SÍ \\
\hline Eslogan & $\begin{array}{l}\text { Manos } \\
\text { expertas }\end{array}$ & $\begin{array}{c}\text { The most } \\
\text { trusted name } \\
\text { in Global } \\
\text { Higher } \\
\text { Education }\end{array}$ & El valor de las ideas \\
\hline $\begin{array}{l}\text { Visibilidad en las } \\
\text { Redes Sociales y Sitios } \\
\text { Web }\end{array}$ & $\begin{array}{l}\text { Facebook } \\
\text { Twitter } \\
\text { YouTube }\end{array}$ & $\begin{array}{c}\text { Facebook } \\
\text { Twitter } \\
\text { YouTube } \\
\text { Google + } \\
\text { Vimeo } \\
\text { Flickr } \\
\text { Pinterest } \\
\text { Tumblr }\end{array}$ & $\begin{array}{l}\text { Facebook } \\
\text { Twitter } \\
\text { YouTube }\end{array}$ \\
\hline Presencia de locutor & $\mathrm{NO}$ & SÍ & SÍ \\
\hline Imágenes & SÍ & SÍ & SÍ \\
\hline $\begin{array}{l}\text { Declaraciones de } \\
\text { personalidades }\end{array}$ & $\mathrm{NO}$ & SÍ & SÍ \\
\hline $\begin{array}{l}\text { Memoria corporativa } \\
\text { en la Página Web }\end{array}$ & $\begin{array}{c}\text { SÍ } \\
132 \text { páginas }\end{array}$ & $\begin{array}{c}\text { SÍ } \\
88 \text { páginas }\end{array}$ & $\begin{array}{c}\text { SÍ } \\
72 \text { páginas }\end{array}$ \\
\hline
\end{tabular}

Fuente: Elaboración propia.

Tras el análisis de los vídeos corporativos, se pueden extrapolar las siguientes premisas:

- El Banco Santander es el que tiene una campaña de comunicación institucional más extensa (5,47 minutos) y el grupo Quirón, la que menos (3,00 minutos).

> Presencia de bandas sonoras atrayentes en la Publicidad Institucional de las tres corporaciones analizadas, por lo que el usuario presta mayor atención y se produce un enriquecimiento del mensaje.

- Las campañas institucionales del Grupo Quirón y de Laureate International Universities son las únicas que presentan un locutor que explica las distintas características y servicios que ofrecen.

Laureate International Universities es la que mayor visibilidad presenta en Redes Sociales y Páginas Web, con un total de 8 apariciones. 
$>$ Todos los grupos corporativos analizados incorporan en los vídeos institucionales imágenes de sus respectivas instalaciones para reforzar su mensaje institucional.

> En la información corporativa del Grupo Quirón y del Banco Santander se insertan títulos sobreimpresionados en las imágenes para conseguir una mayor claridad, visualización y eficacia en la transmisión del mensaje institucional.

Importancia de los eslóganes, ya que contienen una gran carga retórica para reforzar la imagen de la Institución y atraer la atención del receptor. Ejemplos: The most trusted name in Global Higher Education, Manos expertas y El valor de las ideas.

Las campañas institucionales de Laureate International Universities y del Banco Santander son las únicas que ofrecen declaraciones de personalidades destacadas para explicar las características distintivas de la corporación y reforzar su imagen de marca.

$>$ Por lo que respecta a las memorias corporativas, se encuentran integradas por los siguientes apartados: la organización (misión, visión, valores, Consejo de Administración y direcciones corporativas); las sedes; y la Responsabilidad Social Corporativa (Fundación, convenios, capital humano, formación y sostenibilidad), siendo la más extensa la del Grupo Quirón, con 132 páginas.

\section{CONCLUSIONES}

Las empresas deben seleccionar, formar y motivar a sus trabajadores para que realicen cada día tareas más amplias y así tener iniciativa para asumir riesgos calculados, sin pasar la responsabilidad última a sus superiores. La capacidad de cambiar es clave para que cualquier estrategia de gestión sea susceptible de tener éxito. Por eso, las nuevas tendencias dejan de centrarse en los puestos de trabajo y los resultados y buscan personas con capacidades para adaptarse a los cambios.

Así, ya no basta con tener una plantilla bien formada en conocimientos técnicos que siga las directrices de los líderes de la compañía. En este entorno cambiante, hay que valorar más la intuición, que no es más que un atributo de un buen profesional de la comunicación, la capacidad de improvisar y la inteligencia emocional de las personas, en contraposición al acierto intelectual de los directivos.

En este escenario de comunicación corporativa y Web 2.0, las empresas han definido un posicionamiento y han alcanzado una difusión a través de las redes sociales. Eslóganes sugerentes, vídeos institucionales con bandas sonoras atrayentes, memorias corporativas en línea y Páginas Web diseñadas por perfiles de usuarios constituyen las señas de identidad de los grupos corporativos para atraer a su público objetivo. De esta forma, los espacios de desarrollo y exhibición del ámbito empresarial ganan un nuevo aporte desde la Web 2.0, gracias a la creación de canales de comunicación abiertos al público. Ahora es posible que una persona o grupo corporativo pueda tener 
Empresas Web 2.0 - Cultura corporativa - Ética empresarial - Conexión emocional

su propio canal de comunicación con layout personalizado y una oferta de contenido de acuerdo con sus intereses.

Mediante esta nueva realidad, el concepto de aldea global experimenta cambios continuos. Los grupos sociales tienen la oportunidad de crear sus aldeas locales, pero también tienen la posibilidad de mantener su estatus en la aldea global. El uso de este medio está generando nuevas formas de comunicación en la gestión de la información. $\mathrm{Su}$ utilización se ve incrementada por el interés de cada administrador de ser conocido, comentado y refutado por sus pares u otros públicos que puedan compartir sus intereses desde cualquier latitud.

Por tanto, innovación, liderazgo, espíritu de grupo, internacionalidad, orientación profesional y enfoque de resultados constituyen los rasgos diferenciadores de los grupos corporativos analizados. De esta forma, la misión se configura como la razón de ser de la existencia de la empresa y de su adecuada configuración dependen la definición, el desarrollo y el cumplimiento de los fines, los objetivos y las estrategias. En definitiva, estos grupos empresariales han encontrado una forma de comunicación pertinente, avanzada, necesaria y rápida con su Target, sustentada por la Web 2.0, lo que configura un nuevo paradigma en la satisfacción de las necesidades de los usuarios.

\section{BIBLIOGRAFIA}

Aced, C. et al. (2009). Visibilidad: cómo gestionar la reputación en Internet. Barcelona: Gestión 2000.

Barroso, O. (2008). Del portal en la comunicación empresarial a la Web 2.0. La carrera por la empatía con el usuario, RE-Presentaciones Periodismo, Comunicación y Sociedad, 4, 115-122.

Cabrera, M. A. (2010). La interactividad de las audiencias en entornos de convergencia digital. Icono14, 8 (1), 164-177. Disponible en:

www.icono14.net/ojs/index.php/icono14/article/view/287/164

[Fecha de consulta: 14 de febrero de 2013].

Castelló-Martínez, A. (2010). Estrategias empresariales en la Web 2.0. Las redes sociales online. Alicante: ECU.

Celaya, J. (2008). La empresa en la Web 2.0. Madrid: Gestión 2000.

Madinabeitia, E. (2010). La publicidad en medios interactivos. En busca de nuevas estrategias, Telos. Cuadernos de Comunicación e Innovación, 82, 43-54. Disponible en: http:/ / sociedadinformacion.fundacion.telefonica.com/ seccion=1268\&idioma=es ES\&id=2010020211580001\&activo=6.do [Fecha de consulta: 20 de febrero de 2013].

O'Reilly, T. (2005). What is web 2.0. Disponible en: 
www.oreillynet.com/pub/a/oreilly/tim/news/2005/09/30/what-is-web 20.html?page=1) [Fecha de consulta: 25 de marzo de 2013].

Piñuel, J. L. (1997). Teoría de la Comunicación y gestión de las organizaciones. Madrid: Síntesis.

Ros-Diego, V. J. (2008). E-branding. Posiciona tu marca en la Red. A Coruña: Netbiblo.

Sotelo, C. (2007). Introducción a la Comunicación Institucional. Barcelona: Ariel.

Stein, M. (2010). La Comunicación Corporativa a través de la Web 2.0, Conceptia Group Blog. Disponible en: www.conceptiagroup.com/blog/162-la-comunicacioncorporativa-en-laweb-20.html [Fecha de consulta: 20 de marzo de 2013].

Tallón, J. (1992). Lecciones de Empresa Informativa. Madrid: Ediciones de las Ciencias Sociales.

www.quiron.es/es

[Fecha de consulta: 26 de febrero de 2013].

www.laureate.net/

[Fecha de consulta: 10 de marzo de 2013].

www.bancosantander.es/cssa/Satellite?pagename $=$ SantanderComercial $\% 2 \mathrm{FPage} \% 2 \mathrm{~F}$ SAN_Index

[Fecha de consulta: 20 de marzo de 2013].

\section{Carlos Oliva Marañón}

Profesor de la Facultad de Ciencias de la Comunicación de la Universidad Rey Juan Carlos, Departamento de Ciencias de la Comunicación I. Doctor en Ciencias de la Comunicación. Autor, entre otras publicaciones, de las siguientes: Calidad, visibilidad e interactividad: paradigmas de las Universidades Virtuales en España; Las monografías de Publicidad a través de las aplicaciones documentales ISBN y REBIUN: un estudio bibliográfico (2008-2012); El Grado en Cine en las Universidades de España: visibilidad, competencias, contenidos y propuestas de futuro; Creatividad, Publicidad y Educación Emocional: fundamentos del Lipdub como aplicación de la imagen de marca de las Universidades; Fundamentos lingüísticos del lenguaje periodístico y jurídico-administrativo. 
Alfonso de la Quintana García-Pérez

Profesor Titular Interino de la Facultad de Ciencias de la Comunicación de la Universidad Rey Juan Carlos, Departamento de Ciencias de la Comunicación I. Doctor en Ciencias de la Información. Máster en Dirección y Administración de Empresas. Máster en Prevención de Riesgos Laborales. Técnico Superior y Auditor en Prevención de Riesgos Laborales. 